\title{
Effect of Chungpaesagan-tang on ischemic damage induced by MCAO in spontaneously hypertensive rats
}

\author{
Ko-Eun Kim ${ }^{2}$, Soo-Yong Kim ${ }^{1}$, Eun-Young Kim ${ }^{1}$, Bum-Hoi Kim ${ }^{5}$, Jung-Won Shin ${ }^{4}$, Hyun-Sam Lee ${ }^{1}$, \\ Young-joo Sohn ${ }^{3, *}$, Hyuk-Sang Jung ${ }^{1}$ and Nak-Won Sohn ${ }^{2}$ \\ ${ }^{1}$ College of Oriental Medicine, Institute of Oriental Medicine, Kyung Hee University, Republic of Korea; \\ ${ }^{2}$ Graduate School of East-West Medicine, Kyung Hee University, Republic of Korea; ${ }^{3}$ College of Oriental \\ Medicine, Sangji University, Republic of Korea; ${ }^{4}$ School of Medicine, Washington University in St. Louis, USA; \\ ${ }^{5}$ College of Oriental Medicine, Dong-Eui University
}

Received for publication April 01, 2008; accepted September 30, 2008

\begin{abstract}
SUMMARY
Chungpaesagan-tang (CPSGT) is most frequently used to treat ischemic brain injury in tradition Korean medicine. Clinically, cerebral ischemia is likely to be accompanied by preexisting or complicating disease. However, animal models used to examine the effects of herbal medicines on cerebral ischemia have not given this issue sufficient consideration. The present study was undertaken to determine the effects of CPSGT on focal cerebral ischemia in normal and SHR rats subjected to transient middle cerebral artery occlusion (MCAO). Animals were divided into four groups: Normal (Sprague-Dawley) rats subjected to $\mathrm{MACO}$ (the $\mathrm{NC}+\mathrm{MCAO}$ group), normal rats subjected to $\mathrm{MCAO}$ and then administered CPSGT (NC + MCAO + CP), SHR rats subjected to MCAO (SHR + MCAO), and SHR rats subjected to MCAO and then administered CPSGT (SHR + MCAO + CP). MCAO was performed using the intraluminal method. CPSGT was administrated orally twice ( 1 and $4 \mathrm{~h})$ after MCAO. All animals were sacrificed at $24 \mathrm{~h}$ postoperatively. Brain tissues were stained with hematoxylin \& eosin, to examine the effect of CPSGT on ischemic brain tissues. In addition, changes in TNF- $\alpha$ expression in ischemic areas were examined by immunostaining. CPSGT was found to significantly reduce infarction areas in normal and SHR rats and infarction volumes in SHR rats. Similarly, CPGST markedly increased neuron numbers and sizes in all treated groups, except cell sizes in SHRs. Furthermore, CPSGT reduced TNF- $\alpha$ expression in MCAO administered SHR rats. The findings of the present study suggest that CPSGT effectively ameliorates neuron damage caused by MACO-induced cerebral ischemia, and that it has a significant neuroprotective effect after cerebral ischemia in SHR.
\end{abstract}

Keywords: Middle cerebral artery occlusion; Spontaneously hypertensive rats; TNF- $\alpha$; Chungpaesagan-tang

\section{INTRODUCTION}

Ischemic brain injury is a worldwide medical problem that often causes irreversible brain damage. Moreover,

*Correspondence: Young-joo Sohn, College of Oriental Medicine, Sangji University, 283 Woosan-dong, Wonjucity, Kangwon-do, 220-955, Republic of Korea. Tel: +8233-741-9303; E-mail: q701@chollian.net the prevention of ischemic brain injury is key, since the after-effects of stroke significantly jeopardize quality of life. Several risk factors predispose cerebral infarction, e.g., chronic hypertension, diabetes, smoking, and hypercholesteremia, and prognoses are unfavorable in the presence of these risk factors (Wolf et al., 1991). 
Hypertension is a well-known risk factor of atherothrombotic cerebral infarction. Moreover, chronic arterial hypertension greatly reduces the capacity of the cerebral circulation to dilate under conditions of hemorrhagic or drug-induced hypotension. Experimentally, infarct size is greater in spontaneously hypertensive rats (SHR) subjected to focal cerebral ischemia than in normotensive rat strains (Duverger and MacKenzie, 1988; Dogan et al., 1998).

Ischemic injury in SHR rats is more severe than that in normotensive rats, which may be due to differences in the cerebral vasculature. SHR rats have fewer collateral vessels between cerebral vascular territories than other rat strains (Coyle, 1986), and furthermore, vascular anatomies vary substantially in SHR rats (Fox et al., 1993; Niiro et al., 1996). Therefore, middle cerebral artery occlusion (MCAO) in SHR may produce end-arterial ischemia, perhaps due to microcirculatory impairments (Dawson et al., 1997). In addition, as is observed medial hypertrophy (Winquist and Bohr, 1983), in SHR rats results in decreased functional compliance and smaller pial artery diameters as compared with normotensive rats. In addition, hypertension greatly impairs endothelium-mediated dilatation of the cerebral vasculature (Duverger and MacKenzie, 1988; Ginsberg and Busto, 1989). In addition, these changes may restrict the supply of neuroprotectants to ischemic tissues.

It has been previously reported that response to cerebral ischemia in rodents is affected by age, gender, strain and estrous cycle (Carswell et al., 1999). Thus, based on available information, we speculate that the optimal neuroprotective dose required by a stroke patient depends not only on the type and extent of the stroke, but also on additional co-morbid factors, such as, hypertension (Harms et al., 2000).

Chungpaesagan-tang (清肺瀉肝湯, CPSGT) is most frequently used by Korean oriental practitioners to treat ischemic brain injury. Puerariae radix and Cimicifugae rhizoma are drugs for dispersing actions of wind and heat; Scutellariae radix eliminates heat and dampness; Angelicae tenuissimae radix and Angelicae Dahuricae radix have dispersing actions of wind and cold, Raphami Semen is stomachics and evacuants; Platycodi radix is phlegm-resolving drugs with cold properties; Rhei rhizoma is drugs for purgation.

In experimental studies, CPSGT has been found to be effective against disorders of liver (Kim et al., 1978), to influence liver and kidney function (Kim and Ryu, 1983), to reinforce the immune system and attenuate allergy reactions (Kim et al., 1991), and to significantly improve the conditions of diabetic (Koo and Kim, 1997) and obese patients (Song et al, 1998; Heo and kang, 1998). In addition, it has been reported to attenuate the effects of ischemia-reperfusion injury and inflammation reactions (Hong et al., 2000), and to have a positive effect after $\mathrm{MACO} /$ reperfusion in rats in an in vivo study of brain disease (Oh et al., 2001). However, previous studies that have examined the effects of CPSGT on cerebral ischemia have substantial shortcomings. Clinically, cerebral ischemia is likely to be accompanied by a preexisting or complicating disease. However, the animal models used for examining the effects of herbal medicines on cerebral ischemia have not fully addressed this issue.

In the present study, we sought to determine the effects of CPSGT on focal cerebral ischemia in normal and SHR rats subjected to transient middle cerebral artery occlusion (MCAO).

\section{MATERIALS AND METHODS}

\section{Animals}

Rats were fed freely with water and a pelleted layer diet (Jeil Feed Co., Daejeon).

The animals were housed at $21-24^{\circ} \mathrm{C}$ in $50 \pm 10 \%$ humidity environment under a $12 \mathrm{~h}$ light cycle. Prior to experiments, rats were allowed to adapt to the laboratory environment for 2 weeks. Animals (Daehan Bio Link) weighed 250 - $300 \mathrm{~g}$ prior to the testing. Animals were divided into four groups: 
Normal (Sprague-Dawley) rats subjected to MACO (the NC + MCAO group), normal rats subjected to $\mathrm{MCAO}$ and then administered CPSGT (NC + $\mathrm{MCAO}+\mathrm{CP}$ ), SHR rats subjected to MCAO (SHR + MCAO), and SHR rats subjected to MCAO and then administered CPSGT (SHR + MCAO + CP).

Each of the above three groups contained 10 experimental animals. The study was approved by the Institutional Animal Care and Use Committee of Kyung Hee University and all procedures were conducted in accordance with the U.S. National Institutes of Health guidelines.

\section{Preparation and Administration of Medication}

CPSGT was purchase from the Kyung Hee Oriental Medical Center (Seoul, Republic of Korea). Five doses of CPSGT (260 g) were boiled with distilled water (3 L) for $2 \mathrm{~h}$, and the aqueous extract obtained was concentrated using a rotary vacuum evaporator, and lyophilized. $58.2 \mathrm{~g}$ of lyophilized extract was obtained. CPSGT was administered in this form (hereafter referred to as CPSGT) at $193.9 \mathrm{mg} / 100 \mathrm{~g}$ orally at $1 \mathrm{~h}$ or $4 \mathrm{~h}$ post-MCAO. Chungpaesagantang extract was diluted with physiological saline solution. The amount administered was determined by assuming that an adult human of approximately $60 \mathrm{~kg}$ would take about $11.6 \mathrm{~g}$ a day, therefore the rats received $193.9 \mathrm{mg} / 100 \mathrm{~g}$ body weight.

\section{Induction of Cerebral Ischemia}

The intraluminal method of administering MACO described by Longa et al. (1989) was adopted. In addition, a poly-L-lysine coating was applied to 4-0 nylon suture, as described by Belayev et al. (1996) was also used to induce more extensive and stable cerebral ischemia.

The procedures used were as follows. Healthy Sprague-Dawley rats and SHR rats (weighing 250 $300 \mathrm{~g}$ ) were anesthetized with isoflourane (induction $5 \% /$ maintenance $1.5 \%$ ) in an oxygen/nitrous oxide (30:70) mixture. Body temperatures $(37.0 \pm 0.5)$ were maintained using a feedback-regulated heating pad throughout surgery. Blood vessels of anesthetized rats were exposed through a ventral midline incision under an operating microscope (Carl Zeiss, Germany). The external carotid artery (ECA) and the internal carotid artery (ICA) were identified, and both the occipital artery and superior thyroid artery (STA) branches of the ECA, were dissected with an electric coagulator (Nazme, Japan). The distal portion of the ECA was ligated, and further bound with two loops of a 5-0 silk suture. Blood flows in the ICA and CCA were then blocked completely using a 3-0 silk suture and an artery clamp (microvascular clip). A 4-0 nylon suture (Ethilon, England) with a rounded tip, coated with poly-L-lysine solution (Sigma Diagnostics, P8920, $0.1 \% \mathrm{w} / \mathrm{v}$ in water), was then introduced into the ECA lumen to a depth of $c a$. $18-20 \mathrm{~mm}$ after partially incising the ECA with a spring microdissecting scissors. The ICA and CCA were then re-perfused, and then the distal portion of the ECA was dissected.

The procedure was completed by suturing and sterilizing the ventral midline. Following recovery from anesthesia rats were allowed to move freely. Finally, $120 \mathrm{~min}$ after occlusion, reperfusion was facilitated by withdrawing the 4-0 nylon suture.

\section{Histology of Cerebral Ischemia Sacrifice}

Rats were transcardially perfused with $4 \%$ paraformaldehyde (PFA) in phosphate buffer saline (PBS), and brains were immediately removed, fixed in the same fixative solution for $12 \mathrm{~h}$, and cryoprotected by soaking then in $20 \%$ sucrose in $0.1 \mathrm{M}$ phosphate buffer for $24 \mathrm{~h}$. They were then embedded in Tissue-Tek O.C.T. compound, and frozen quickly using $\mathrm{CO}_{2}$. 25 um sections were then cut in the coronal plane using a cryostat at $-20^{\circ} \mathrm{C}$. Sections were gathered in $0.02 \mathrm{M}$ PBS, and preserved in stock solution.

Measurement of cerebral ischemia areas and volumes Sections coated with gelatin were dried on slides for $24 \mathrm{~h}$, stained with hematoxylin and eosin, and scanned (Epson, GT-9500, Japan) to determine infarct 
areas and volumes. All brain section images were measured using "NIH Image" software (NIH, Ver. 1.66 , USA) on an imaging analysis system (Macintosh, Power PC G3, USA). Infarct areas (A) were determined after correcting for edema formation in damaged hemispheres. Areas of intact hemispheres (B) were measured, as were undamaged areas in damaged hemispheres (C). Infarct areas (A) were calculated by subtracting undamaged areas from intact hemisphere areas (i.e., $\mathrm{A}=\mathrm{B}-\mathrm{C}$ ). Total infarct volumes were calculated using the following formula (Swanson et al., 1990).

Total Infarct Volume $\left(\mathrm{mm}^{3}\right)=$

$\frac{\text { Sarea }\left(\mathrm{mm}^{2}\right) \text { per side }}{\text { No. of sides analyzed }}$

$\times 12 \mathrm{~mm}$ (Max. extent of infarct)

\section{Neuron cells - observations and measurements}

Section histologies were examined under a light microscope (Olympus, VANOX AHBS-3, Japan, magnification $\times 200$ ), and the images of damaged neurons were entered into a computer system (Macintosh, Power PC G3, USA). To measure infarct volumes and neuron numbers, cells larger than 20 um were measured in a set region of interest in the cortex (320 um $\times 466 \mathrm{um}$ ) among slices of interaural 6 mm using "NIH Image" software (NIH, Ver. 1.66, USA) (Fig. 1).

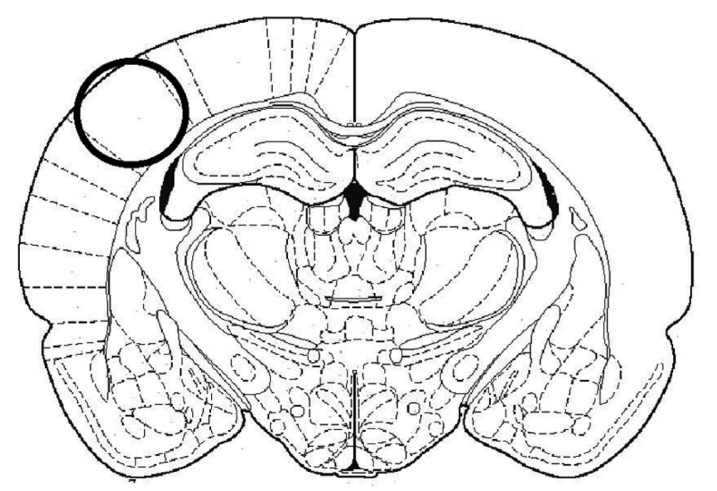

Fig. 1. Schematic diagram of a coronal section of rat brain (interaural $6 \mathrm{~mm}$ ). Cell numbers and number of cells larger than $20 \mathrm{um}^{2}$ in the circle shown were determined by light microscopy $(\times 200)$.

\section{Immunohistochemistry}

Immunohistochemistry was performed using the floating method. Frozen sections were rinsed with $0.1 \mathrm{M}$ PB solution, and rinsed for $3 \times 15$ mins with $0.02 \mathrm{M}$ PBS solution to remove O.C.T. compound. Sections were then treated with $10 \%$ normal goat serum for $1 \mathrm{~h}$ at 4 to prevent unspecified immune reactions, and then treated with primary antibody diluted $(1: 1000)$ with PBS solution containing $1 \%$ NGS and $1 \%$ bovine serum albumin (BSA) for $48 \mathrm{~h}$ at 4 . Sections were then washed with PBS $(3 \times 15$ $\mathrm{min})$, incubated with biotinylated goat-anti rabbit immunoglobulin $\mathrm{G}$ as secondary antibody $(1: 500$ dilution in PBS) for $24 \mathrm{~h}$ at 4 , and rewashed with PBS $(3 \times 15 \mathrm{~min})$. Sections were then incubated with $\mathrm{ABC}$ (avidin-biotin peroxidase complex, A: 10 $\mathrm{ul}, \mathrm{B}: 10 \mathrm{ul}$ in $1 \mathrm{ml}$ PBS) solution, which was prepared $30 \mathrm{~min}$ before application, for $1 \mathrm{~h}$ at room temperature, and consecutively washed with PBS solution and Tris-HCl buffer (TB, $0.05 \mathrm{M}, \mathrm{pH}$ 7.4) three times for $15 \mathrm{~min}$ each. They were then incubated sequentially with a mixed substrate solution containing TB and $0.05 \%$ 3,3'-diaminobenzidine tetrahydrochloride (DAB) for $30 \mathrm{~min}$ at room temperature, and a mixed substrate solution containing $\mathrm{TB}, \mathrm{DAB}$, and $0.03 \%$ hydrogen peroxide for 5 - $10 \mathrm{~min}$. Finally, they were washed with TB and PBS solutions, respectively, and then enclosed and examined.

\section{Statistical analysis}

All results were tested for significance using the Student's $t$-test and a probability level of $95 \%$.

\section{RESULTS}

\section{Changes in areas of focal cerebral ischemia}

Focal cerebral ischemia induced in normal rats (NC + MCAO group) was compared with that induced in SHR rats (SHR + MCAO group). In both groups, infarct areas were observed in all sections (from interaural $12 \mathrm{~mm}$ to $2 \mathrm{~mm}$ ). In particular, interaural $8 \mathrm{~mm}$ sections seemed to contain most 


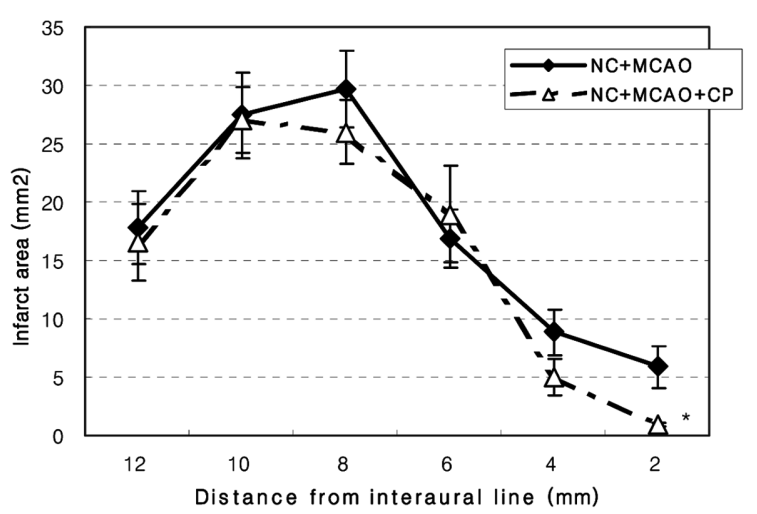

Fig. 2. Infarct areas in brain sections $12 \mathrm{~mm}$ to $2 \mathrm{~mm}$ from the interaural line. $\mathrm{NC}+\mathrm{MCAO}$ (MCAO administered Sprague-Dawley-rats); NC + MCAO + $\mathrm{CP}$ (Sprague-Dawley administered MCAO and then Chungpaesagan $(\mathrm{CP})$ ). Error bars indicate standard errors of means. ${ }^{*} p<0.05$ compared to the $\mathrm{NC}+$ MCAO group.

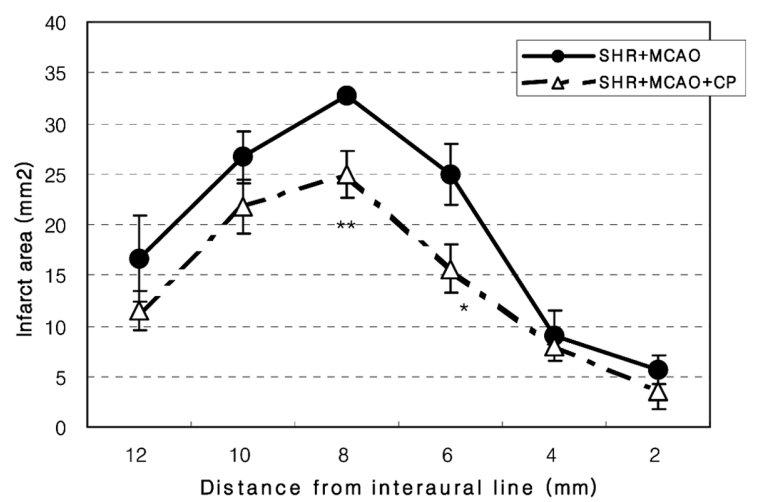

Fig. 3. Infarct areas in brain sections taken $12 \mathrm{~mm}$ to 2 $\mathrm{mm}$ from the interaural line. SHR + MCAO (MCAO administered SHR rats); SHR + MCAO + CP (SHR rats administered $\mathrm{MCAO}$ and then $\mathrm{CP}$ ). Error bars indicate standard errors of means. ${ }^{*} p<0.05,{ }^{* *}<0.01$ compared to the SHR + MCAO group, respectively.

damage in both groups (Figs. $2 \& 3$ ).

In the NC+MCAO group, infarct areas of 17.84 $\pm 3.11 \mathrm{~mm}^{2}, 27.47 \pm 3.69 \mathrm{~mm}^{2}, 29.72 \pm 3.25 \mathrm{~mm}^{2}$, $16.89 \pm 2.52 \mathrm{~mm}^{2}, 8.88 \pm 1.94 \mathrm{~mm}^{2}, 5.88 \pm 1.80 \mathrm{~mm}^{2}$ (from interaural $12 \mathrm{~mm}$ to $2 \mathrm{~mm}$, respectively) were observed. In the $\mathrm{NC}+\mathrm{MCAO}+\mathrm{CP}$ group (CPSGT administered) the corresponding infarct areas were; $16.55 \pm 3.26 \mathrm{~mm}^{2}, 27.01 \pm 2.81 \mathrm{~mm}^{2}, 26.00 \pm 2.73 \mathrm{~mm}^{2}$, $18.92 \pm 4.14 \mathrm{~mm}^{2}, 4.99 \pm 1.55 \mathrm{~mm}^{2}, 0.93 \pm 0.22 \mathrm{~mm}^{2}$. A statistically significant $(\mathrm{P}<0.05)$ reduction in infarct area was observed in the interaural $2 \mathrm{~mm}$ section of $\mathrm{NC}+\mathrm{MCAO}+\mathrm{CP}$ group compared with $\mathrm{NC}+$ MCAO group (Fig. 2).

In the SHR + MCAO group, the corresponding infarct areas were $16.61 \pm 4.25 \mathrm{~mm}^{2}, 26.67 \pm 2.56 \mathrm{~mm}^{2}$, $32.78 \pm 0.56 \mathrm{~mm}^{2}, 24.97 \pm 3.08 \mathrm{~mm}^{2}, 8.98 \pm 2.47 \mathrm{~mm}^{2}$, $5.66 \pm 1.37 \mathrm{~mm}^{2}$, and in the SHR + MCAO + CP group these were $11.58 \pm 1.95 \mathrm{~mm}^{2}, 21.73 \pm 2.70 \mathrm{~mm}^{2}$, $24.87 \pm 2.30 \mathrm{~mm}^{2}, 15.63 \pm 2.36 \mathrm{~mm}^{2}, 8.01 \pm 1.01 \mathrm{~mm}^{2}$, $3.49 \pm 1.73 \mathrm{~mm}^{2}$. Infarct areas in these groups tended to decrease when animals were treated with CP. In particular, significant reduction in infarct areas occurred in interaural $8 \mathrm{~mm}(p<0.01)$ and $6 \mathrm{~mm}$ sections $(p<0.05)$ (Fig. 3).

\section{Changes in focal cerebral ischemia volumes}

Mean infarct volumes in the $\mathrm{NC}+\mathrm{MCAO}$ and $\mathrm{SHR}+\mathrm{MCAO}$ groups were $210.00 \pm 18.70 \mathrm{~mm}^{3}$ and $231.31 \pm 18.77 \mathrm{~mm}^{3}$, respectively, which were not statistically significant. mean infarct volume was lower in the $\mathrm{NC}+\mathrm{MCAO}+\mathrm{CP}$ group (188.79 $\pm 24.39 \mathrm{~mm}^{3}$ ) than in the $\mathrm{NC}+\mathrm{MCAO}$ group, but this was also not significant (Fig. 4). However, mean infarct volume in the SHR + MCAO + CP group $\left(170.61 \pm 16.18 \mathrm{~mm}^{3}\right)$ was significantly $(P<0.05)$ lower than in the SHR + MCAO group (Fig. 4).

\section{Changes in numbers of neuron cells}

The mean number of neuron cells in the normal cerebral cortex was $172.60 \pm 6.30$. Moreover, the

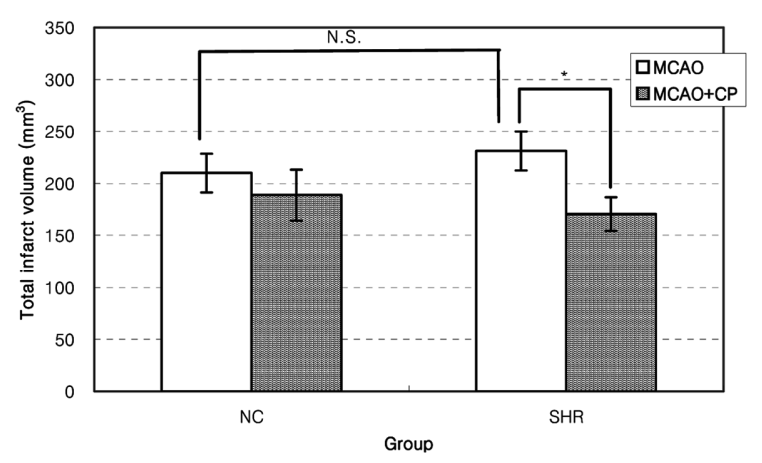

Fig. 4. Total infarct volume in each group. Error bars indicate standard errors of means. ${ }^{*} p<0.05$ compared to MCAO group. 

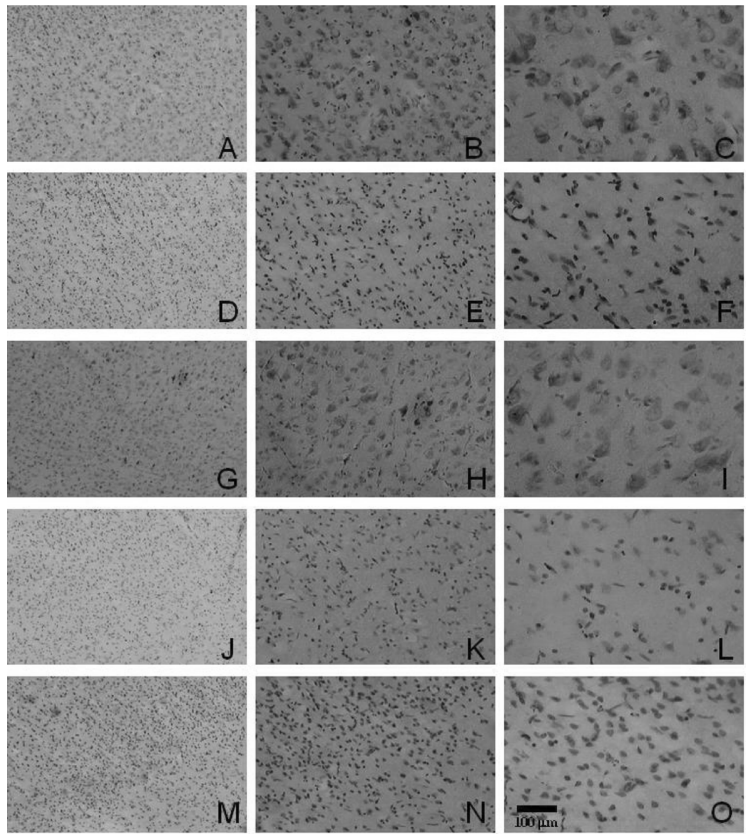

Fig. 5. Sections demonstrates MCA occluded cortexes stained with cresyl violet (magnification A, D, G, J, M: 100X; B, E, H, K, N: 200X; C, F, I, L, O: 400X). (A - C) show neuron cells in the normal brain cortex. (D - F) show neurons in the NC + MCAO cortex, (G - I) neurons in the $\mathrm{NC}+\mathrm{MCAO}+\mathrm{CP}$ cortex, $(\mathrm{J}-\mathrm{L})$ neurons in the SHR + MCAO cortex, and $(\mathrm{M}-\mathrm{N})$ neurons in the SHR + MCAO + CP cortex.

number of neuron cells in the penumbral region (boundaries between infarcted and normal areas) was markedly less $(P<0.01$ each) than in intact regions in the $\mathrm{NC}+\mathrm{MCAO}$ and $\mathrm{SHR}+\mathrm{MCAO}$ groups. However, CPSGT significantly $(P<0.001)$ increased intact neuron numbers from $97.33 \pm 3.18$ to $159.50 \pm 8.50$ in the $\mathrm{NC}+\mathrm{MCAO}+\mathrm{CP}$ group versus the NC + MCAO group (Table 4, Fig. 5). Similarly, CPSGT significantly $(P<0.001)$ increased intact neuron numbers from $86.50 \pm 3.86$ to $143.00 \pm$
Table 1. Composition of Chungpaesagan-tang

\begin{tabular}{ccc}
\hline Herbs & Pharmaceutics & Weight $(\mathrm{g})$ \\
\hline 葛根 & Puerariae Radix & 16 \\
黃芩 & Scutellariae Radix & 8 \\
葍本 & Angelicae tenuissimae Radix & 8 \\
羅服子 & Raphami Semen & 4 \\
桔梗 & Platycodi Radix & 4 \\
白芷 & Angelicae Dahuricae Radix & 4 \\
升麻 & Cimicifugae Rhizoma & 4 \\
大黃 & Rhei Rhizoma & 4 \\
\hline Total & & 52
\end{tabular}

4.36 in the $\mathrm{SHR}+\mathrm{MCAO}+\mathrm{CP}$ group versus the SHR + MCAO group (Table 2, Fig. 5).

\section{Changes in neuron sizes}

The mean size of neuron cells in normal cerebral cortexes was $53.66 \pm 1.47 \mu \mathrm{m}^{2}$. Moreover, neurons were smaller in penumbral regions than in intact regions, in both the NC + MCAO and SHR + MCAO groups. Furthermore, CPSGT significantly $(P<0.01)$ increased neuron sizes from $37.80 \pm 1.24 \mu^{2}$ to $39.25 \pm 1.72 \mu \mathrm{m}^{2}$ in the $\mathrm{NC}+\mathrm{MCAO}+\mathrm{CP}$ group versus the NC + MCAO group (Table 2). Similarly, CPSGT increased mean neuron size from $33.35 \pm$ $1.62 \mu \mathrm{m}^{2}$ to $37.69 \pm 1.00 \mu \mathrm{m}^{2}$ in the SHR + MCAO + $\mathrm{CP}$ group versus the SHR + MCAO group (Table 2, Fig. 5).

\section{Changes in TNF- $\alpha$ expression}

TNF- $\alpha$ expression in the penumbral region after MCA occlusion was rarely observed in the focal cerebral ischemia regions in normal rats, but was in SHR rats. Furthermore, TNF- $\alpha$ immunostained was markedly lower in the SHR $+\mathrm{MCAO}+\mathrm{CP}$ group than in the SHR + MCAO group (Fig. 6).

Table 2. Numbers and sizes of neuron Cells

\begin{tabular}{lcc}
\hline & Number of neuron cells & Size of neuron cells $\left(\mathrm{um}^{2}\right)$ \\
\hline Intact & $172.60 \pm 6.30$ & $53.66 \pm 1.47$ \\
$\mathrm{NC}+\mathrm{MCAO}$ & $97.33 \pm 3.18$ & $37.80 \pm 1.24$ \\
$\mathrm{NC}+\mathrm{MCAO}+\mathrm{CP}$ & $159.50 \pm 8.50^{* * *}$ & $39.25 \pm 1.72$ \\
$\mathrm{SHR}+\mathrm{MCAO}$ & $86.50 \pm 3.86$ & $33.35 \pm 1.62$ \\
$\mathrm{SHR}+\mathrm{MCAO}+\mathrm{CP}$ & $143.00 \pm 4.36^{+++}$ & $37.69 \pm 1.00$ \\
\hline
\end{tabular}

Data present means \pm standard errors. ${ }^{* *,+++} p<0.001$ compared to the NC + MCAO and SHR + MCAO groups. 

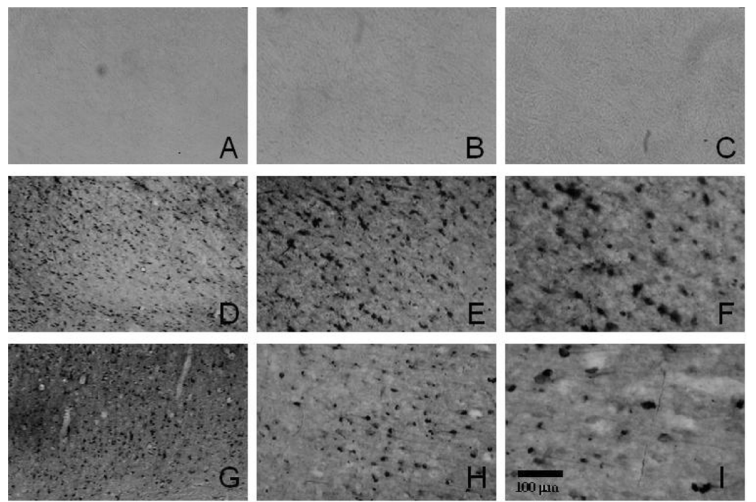

Fig. 6. The effect of $\mathrm{CP}$ on focal cerebral ischemia induced TNF- $\alpha$ expression (magnification A, D, G: 100X; B, E, F: 200X; G, H, I: 400X). Tissue sections were immunostained with antibodies against TNF- $\alpha$ as described in Materials and Methods. (A - C) Normal brain section showing no expression of TNF- $\alpha$. (D - F) Ischemic section showing TNF- $\alpha$ in the SHR. (G - I) Brain from the $\mathrm{SHR}+\mathrm{MCAO}+\mathrm{CP}$ group rats showing little TNF- $\alpha$ expression.

\section{DISCUSSION}

Cerebral ischemia reduces cerebral blood flow and oxygen supply, and leads to neuronal cell death. This process is caused by energy depletion and inflammatory reactions. When cerebral ischemia occurs, neurons depolarize, synaptic glutamate is released and glutamate accumulates extracellularly. Furthermore, extracellular glutamate accumulation is accelerated by the reversal of active glutamate transport, due to reduced ATP levels. This extracellular glutamate released by $\mathrm{Ca}^{2+}$-dependent exocytosis induces excessive intracellular $\mathrm{Ca}^{2+}$ influx largely through potentiated NMDA-receptorchannels, which leads to free radical production via the activation of $\mathrm{Ca}^{2+}$-dependent protease, lipase, and various other modulators. Eventually, these free radicals destroy the cellular structure and induce neuronal death. In addition, decreases in intracellular polyamines, which are known to scavenge free radicals (Adibhatla et al., 2002) and an increase in hydroxyl radicals (Negishi et al., 2001), are also evident after focal cerebral ischemia. Furthermore, nitric oxide (NO), which is known to regulate brain metabolism and blood flow and to participate in NMDA receptor-mediated neural toxicity, has been reported to have a significant influence on cerebral ischemia (Dawson and Snyder, 1994; Dobrucki et al., 2000; Hamada et al., 1995). The inflammatory reactions of ischemia are preceded by an accumulation of neutrophils, increases in cytokines and their activations, and increases in blood cell adhesion molecules, and astrocyte numbers. During the early stage of the post-ischemic inflammation reaction, granulocytes, such as, neutrophils and eosinophils, are recruited from blood, whereas during the late stage, $\mathrm{T}$ cells and macrophages infiltrate ischemic and boundary zones. Consequently, neuron cell damage becomes irreversible even if the blood circulation is fully restored. It has been reported that the inflammation reactions in microglia are more prominent in focal cerebral ischemia in SHR rats than in normal rats (Marks et al., 2001).

In terms of post-ischemic morphologic changes shown by neurons, in the present study, cell sizes in the cortex reduced from $86.2 \pm 14.6 \mu \mathrm{m}$ to $26.2 \pm$ $13.5 \mu \mathrm{m}$ (i.e., by 69.6\%). Moreover, Bartus et al. (1995) reported that numbers of neurons larger than 20 ìmdecreased from $95.6 \pm 10.4$ to $2.3 \pm 3.7$ (by $97.6 \%$ ) after the permanent occlusion of the proximal part of the MCA (Bartus et al., 1995). In the present study, a similar result was obtained, although the section thickness and magnification used were somewhat different. In the $\mathrm{SHR}+\mathrm{MCAO}+\mathrm{CP}$ group, neuron sizes were $7.6 \%$ lower and cell numbers were $26.9 \%$ lower than SHR + MCAO group. Accordingly, the present study shows that CPSGT has a significant neuroprotective effect on the neurons of the cortex after cerebral ischemia.

In the model of permanent $\mathrm{MCAO}$, infarct volumes were maximal at $6 \mathrm{~h}$, and MCAO increases to 9 or $24 \mathrm{~h}$ had no further effect (Aronowski et al., 1999). Moreover, cerebral blood flow is poorer in the lateral part of the caudate putamen than in the cortex (Nagasawa and Kogure, 1989). Significant reductions in neuron numbers are known to occur 
in the cortex 3 - $6 \mathrm{~h}$ after occlusion (Nakane et al., 1998). In models of transient ischemia, cell death occurs sporadically in the ischemic core after 10-20 min of occlusion, and infarction forms in the ischemic core $1 \mathrm{~h}$ after occlusion. Furthermore, cell death in the ischemic core is generally necrotic, whereas death in the penumbral region is apoptotic. Moreover, neuron necrosis cell starts in the corpus striatum and then in the cortex.

Two types of neuronal changes are induced by $\mathrm{MCAO}$, i.e., acute changes, such as, shrinkage and swelling, which are prominent $6 \mathrm{~h}$ after MCAO, and delayed changes, such as, necrosis, which affect large numbers of neurons from 6 to $12 \mathrm{~h}$ after MCAO (Garcia et al., 1995). Therefore, treatments that target the cerebral ischemia focus after apoptosis has occurred in the penumbral region and in areas surrounding ischemic cerebral tissue, can possibly be avoided if therapeutic measures are taken during the acute stage (Nagasawa and Kogure, 1989; Garcia et al., 1995; Aronowski et al., 1999).

TNF- $\alpha$ is a protagonist of intrinsic inflammatory reactions after brain ischemia (Buttini et al., 1996), and facilitates the infiltrations of inflammatory cells, which can further exacerbate tissue damage (Liu et al., 1994). In addition, TNF- $\alpha$ inhibition was found to attenuate infarct volume (Meistrell et al., 1997; Nawashiro et al., 1997; Yang et al., 1998), and it has been suggested that the inhibition of TNF- $\alpha$ provides a means of treating ischemic stroke (Barone et al., 1997). On the other hand, TNF- $\alpha$ is also known to participate in damaged tissue recovery (Barger et al., 1995).

In this study, infarctions were more prominent in SHR rats, which supports the view that hypertension adversely affects cerebral ischemia. Furthermore, this findings concurs with those of others who concluded that prognosis in cerebral ischemia worsens in the presence of complications and comorbidity factors.

In conclusion, in the present study, CPSGT was found to repress cerebral ischemia regardless of preexisting conditions or complications, and all animals treated with CPSGT showed reductions in cerebral ischemia. As mentioned above, the main treatment target after cerebral ischemia is not necrosis of the core, but rather apoptosis of the penumbral region. Our findings indicate that CPSGT effectively ameliorated neuron damage in the penumbral region, and that it markedly reduced ischemia in SHR rats. In view of the reduced levels of TNF- $\alpha$, CPSGT might attenuate infarct volume via an anti-inflammatory cytokine related effect.

\section{REFERENCES}

Adibhatla RM, Hatcher JF, Sailor K, Dempsey RJ. (2002) Polyamines and central nervous system injury: spermine and spermidine decrease following transient focal cerebral ischemia in spontaneously hypertensive rats. Brain Res. 938, 81-86.

Aronowski J, Cho KH, Strong R, Grotta JC. (1999) Neurofilament proteolysis after focal ischemia; when do cells die after experimental stroke? J. Cereb. Blood Flow Metab. 19, 652-660.

Barger SW, Horster D, Furukawa K, Goodman Y, Krieglstein J, Mattson MP. (1995) Tumor necrosis factors alpha and beta protect neurons against amyloid beta-peptide toxicity: evidence for involvement of a kappa B-binding factor and attenuation of peroxide and $\mathrm{Ca}^{2+}$ accumulation. Proc. Natl. Acad. Sci. USA. 92, 9328-9332.

Barone FC, Arvin B, White RF, Miller A, Webb CL, Willette RN, Lysko PG, Feuerstein GZ. (1997) Tumor necrosis factor-alpha. A mediator of focal ischemic brain injury. Stroke 28, 1233-1244.

Bartus RT, Dean RL, Cavanaugh K, Eveleth D, Carriero DL, Lynch G. (1995) Time-related neuronal changes following middle cerebral artery occlusion: implications for therapeutic intervention and the role of calpain. J. Cereb. Blood Flow Metab. 15, 969-979.

Belayev L, Alonso OF, Busto R, Zhao W, Ginsberg MD. (1996) Middle cerebral artery occlusion in the rat by intraluminal suture. Neurological and pathological evaluation of an improved model. Stroke 27, 16161623.

Buttini M, Appel K, Sauter A, Gebicke-Haerter PJ, Boddeke HW. (1996) Expression of tumor necrosis factor alpha after focal cerebral ischaemia in the rat. 
Neuroscience 71, 1-16.

Carswell HV, Anderson NH, Clark JS, Graham D, Jeffs B, Dominiczak AF, Macrae IM. (1999) Genetic and gender influences on sensitivity to focal cerebral ischemia in the stroke-prone spontaneously hypertensive rat. Hypertension 33, 681-685.

Coyle P. (1986) Different susceptibilities to cerebral infarction in spontaneously hypertensive (SHR) and normotensive Sprague-Dawley rats. Stroke 17, 520-525.

Dawson DA, Ruetzler CA, Hallenbeck JM. (1997) Temporal impairment of microcirculatory perfusion following focal cerebral ischemia in the spontaneously hypertensive rat. Brain Res. 749, 200-208.

Dawson TM, Snyder SH. (1994) Gases as biological messengers: nitric oxide and carbon monoxide in the brain. J. Neurosci. 14, 5147-5159.

Dobrucki LW, Kalinowski L, Uracz W, Malinski T. (2000) The protective role of nitric oxide in the brain ischemia. J. Physiol. Pharmacol. 51, 695-703.

Dogan A, Baskaya MK, Rao VL, Rao AM, Dempsey RJ. (1998) Intraluminal suture occlusion of the middle cerebral artery in Spontaneously Hypertensive rats. Neurol. Res. 20, 265-270.

Duverger D, MacKenzie ET. (1988) The quantification of cerebral infarction following focal ischemia in the rat: influence of strain, arterial pressure, blood glucose concentration, and age. J. Cereb. Blood Flow Metab. 8, 449-461.

Fox G, Gallacher D, Shevde S, Loftus J, Swayne G. (1993) Anatomic variation of the middle cerebral artery in the Sprague-Dawley rat. Stroke 24, 20872093.

Garcia JH, Liu KF, Ho KL. (1995) Neuronal necrosis after middle cerebral artery occlusion in Wistar rats progresses at different time intervals in the caudoputamen and the cortex. Stroke 26, 636-643.

Ginsberg MD, Busto R. (1989) Rodent models of cerebral ischemia. Stroke 20, 1627-1642.

Hamada J, Greenberg JH, Croul S, Dawson TM, Reivich M. (1995) Effects of central inhibition of nitric oxide synthase on focal cerebral ischemia in rats. J. Cereb. Blood Flow Metab. 15, 779-786.

Harms H, Wiegand F, Megow D, Prass K, Einhaupl KM, Dirnagl U. (2000) Acute treatment of hypertension increases infarct sizes in spontaneously hypertensive rats. Neuroreport. 11, 355-359.
Heo SY, Kang HS. (1998) Experimental Study on the Effect of Chungpesagantang in Obese Rats. Korean Acad. Orient. Rehabil. Med. 8, 106-126.

Hong SK, Kang BJ, Kim YJ, Jo DW, Kang SM. (2000) Protective effect of Chungpesagan-tang against ischemia/reperfusion induced cell injury. Dissertation collect. Korean Inst. of Orient. Med. 5, 111-117.

Kim DK, Ryu KW. (1983) Effects of ChungpesaganTang on the Liver and Kidney Dysfunction due to Mercuric Chloride Poisoning in Rabbits. Korean Orient. Med. Soc. 4, 3-29.

Kim DL, Goh BG, Song IB. (1991) An Experimental Study of the Effect by Chongshimyonjatang and Chongpyesagantang on Immune Response and Anti-Allergic Reaction to Rats and Mice. Dissertation collect. Kyung-Hee Univ. 14, 131-160.

Kim JJ, Kim HJ, Ahn BG, Hong WS, Lee SI, Kim WH, Lee HI, Ahn DK, Shin MK. (1978) Studies on the Therapeutics for Liver Diseases in Herb Remedies(II) Experimental Study on the Effect of ChungpesakanTang. Dissertation collect. Kyung-Hee Univ. 1, 9-14.

Koo JS, Kim JH. (1997) Effects of Chungpyesagantang on the Diabetic Rats induced by Strep tozotocin. Assoc. Korean Orient. Ped. 11, 227-248.

Liu T, Clark RK, McDonnell PC, Young PR, White RF, Barone FC, Feuerstein GZ. (1994) Tumor necrosis factor-alpha expression in ischemic neurons. Stroke 25, 1481-1488.

Longa EZ, Weinstein PR, Carlson S, Cummins R. (1989) Reversible middle cerebral artery occlusion without craniectomy in rats. Stroke 20, 84-91.

Marks L, Carswell HV, Peters EE, Graham DI, Patterson J, Dominiczak AF, Macrae IM. (2001) Characterization of the microglial response to cerebral ischemia in the stroke-prone spontaneously hypertensive rat. Hypertension 38, 116-122.

Meistrell ME, Botchkina GI, Wang H, Di Santo E, Cockroft KM, Bloom O, Vishnubhakat JM, Ghezzi $\mathrm{P}$, Tracey KJ. (1997) Tumor necrosis factor is a brain damaging cytokine in cerebral ischemia. Shock 8, 341-348.

Nagasawa H, Kogure K. (1989) Correlation between cerebral blood flow and histologic changes in a new rat model of middle cerebral artery occlusion. Stroke 20, 1037-1043.

Nakane H, Yao H, Ibayashi S, Kitazono T, Ooboshi H, Uchimura H, Fujishima M. (1998) Protein kinase C 
modulates ischemia-induced amino acids release in the striatum of hypertensive rats. Brain Res. 782, 290-296.

Nawashiro H, Martin D, Hallenbeck JM. (1997) Inhibition of tumor necrosis factor and amelioration of brain infarction in mice. J. Cereb. Blood Flow Metab. 17, 229-232.

Negishi H, Ikeda K, Nara Y, Yamori Y. (2001) Increased hydroxyl radicals in the hippocampus of stroke-prone spontaneously hypertensive rats during transient ischemia and recirculation. Neurosci. Lett. 306, 206-208.

Niiro M, Simon RP, Kadota K, Asakura T. (1996) Proximal branching patterns of middle cerebral artery (MCA) in rats and their influence on the infarct size produced by MCA occlusion. J. Neurosci. Methods 64, 19-23.

Oh YH, Jung SH, Park IS, Shin KJ, Lee WC. (2001) The Effects of Chungpesagan-Tang Extracts on Reversible Forebrain Ischemia in Sprague-Dawley Rats. Korean
Soc. Orient. Intern. Med. 22, 161-174.

Song MY, Lee JS, Kim SS, Shin HD. (1998) The clinical study about the effect of Chungpaesagan-Tang and Taeumjowui-Tang on the Taeumin obesity after fa sting therapy. Korean Acad. Orient. Rehabil. Med. 8, 34-56.

Swanson RA, Morton MT, Tsao-Wu G, Savalos RA, Davidson C, Sharp FR. (1990) A semiautomated method for measuring brain infarct volume. J. Cereb. Blood Flow Metab. 10, 290-293.

Winquist RJ, Bohr DF. (1983) Structural and functional changes in cerebral arteries from spontaneously hypertensive rats. Hypertension 5, 292-297.

Wolf PA, D'Agostino RB, Belanger AJ, Kannel WB. (1991) Probability of stroke: a risk profile from the Framingham Study. Stroke 22, 312-318.

Yang GY, Gong C, Qin Z, Ye W, Mao Y, Bertz AL. (1998) Inhibition of TNFalpha attenuates infarct volume and ICAM-1 expression in ischemic mouse brain. Neuroreport 9, 2131-1234. 